\title{
Interactive Mobile Learning for Self-directed Learning of English Language: A Case Study of a Primary School in Hong Kong
}

\author{
Wilton. W. T. Fok, K. W. Lam, and Prajna. C. W. Ho
}

\begin{abstract}
The importance of Self-directed learning (SDL) in education is increasing in the recent years. It helps promote students' lifelong learning attitudes and improve the learning effectiveness. This stud evaluates the efficiency and effectiveness of using SDL for teaching a group of students with the use of an innovative mobile learning technology "iClass" which facilitates real-time interactive class via a cloud-based platform. The results demonstrate that interactive mobile learning is a good solution to engage students in lesson and to uplift the effectiveness of self-directed learning.
\end{abstract}

Index Terms-Self-directed learning, mobile learning, English education.

\section{INTRODUCTION}

In the last decade of Hong Kong, Self-directed learning (SDL) has been progressively promoted in primary and secondary schools as a critical learning to learn skills and attributes (the Education Bureau, 2017) [1].

With the advantages of learning "anytime anywhere" (Kukulska-Hulme, Agnes and Shield, Lesley, (2008) [2] and the surge of the number of language learning mobile applications available on the application shelves, Mobile-assisted Language Learning (MALL) has increasingly seized the attention of language education researchers. The question of how to unleash the usability of mobile technology to achieve higher proficiency of English language become attachable to their teaching and learning. New pedagogies and suitable e-Learning Management platforms have been created to support knowledge transfer, skills learning, and further facilitation for a greater impact of self-directed learning.

The purpose of this study is to support the fact that Mobile-assisted Language learning and a well-designed Learning Management System (LMS) could be the motivation drivers for students towards self-directed learning while teachers act as the facilitator to enhance students' learning effectiveness. A case study on English Language learning will be discussed.

\section{LITERATURE REVIEW}

In wake of the irreversible trend of mobile technology, the

Manuscript received November 12, 2017; revised January 2, 2018.

Wilton. W. T. Fok and Prajna. C. W. Ho are with the University of Hong Kong, Hong Kong (e-mail: wtfok@eee.hku.hk).

K. W. Lam is with Fung Kai No. 1 Primary School, Hong Kong. increasing number of research studies related to the use of mobile technology in education(see Attewell, 2005 [3]; Churchill, Kennedy, Flint, \& Cotton, 2010 [4]; Kaleebu, Gee, Jones, \& Watson, 2013 [5]; Looi et al., 2010 [6]; Ratto, Shapiro, Truong \& Griswold, 2003 [7]; Shen, Wang, Gao, Novak \& Tang, 2009 [8]; Song \& Fox, 2008 [9]; Wong, Chin, Tan, \& Liu, 2010 [10]; Wong \& Looi, 2011 [11]; Zurita \& Nussbaum, 2004) [12] shows that mobile learning is an important area for the development in education at all levels (Lim, Churchill, 2016) [13].

Flipped learning is a newly-developed and practiced pedagogies in Hong Kong. It is a way to facilitate self-directly learning in primary and secondary schools in Hong Kong. "The flipped classroom" is an instructional model in which the students are initially exposed to the subject matter outside of classroom through video lectures or other pre-class learning materials. It utilizes class time for active learning. (Taotao Long, Joanne Logan, John Cummins, Michael Waugh, 2016 [14]; Gannod, G., Burge, J., \& Helmick, M., 2008[15]; Gerstein, 2011 [16]; Warter-Perez \& Dong, 2012 [17])

In fact, few studies have examined the effects of mobile devices (e.g., Lu, 2008; Song \& Fox, 2008 [9]; Stockwell, 2010 [18]). They were carried out in Asian countries including Hong Kong. A significant portion of research seems to have taken place in a rather restricted number of regions (Lee, H., \& Lee, J. H., 2013) [19]. Therefore, a case study on achieving SDL with mobile technology is discussed in this paper.

\section{APPROACHES OF SDL}

SDL is only achievable when students possess a sense of self-awareness of their own beliefs, strengths, abilities, strategies, and accept the responsibility for their learning. In this regard, students should be provided with an encouraging environment, ample time and authentic contexts to actively and confidently make connections with existing knowledge and apply them in real-life contexts, to co-construct knowledge with peers, and most importantly, to be responsible for their own learning and become Self-directed learners. (The Education Bureau, 2017) [1]. Thus, driving students for Self-directed learning requires certain elements of the learner himself; the quality of facilitators and the environment. The objective of achieving SDL in learning can be continuously challenging even for the most motivated students. Some approaches of exploiting the technology to facilitate Self-direct learning are shared as follows:

First, we should allow student to have control over as 
much of the learning experience as possible. How to motivate students to learn by themselves is one of the difficult questions to answer (Self-motivation is one of the most difficult skills to acquire). Teachers do wish that students can acquire some basic knowledge by themselves so that they can spare more face to face meeting time for interactive activities. Students' self-learning can be achieved with mobile technology. Not only does it offer a spectrum of tools for teachers to create educational opportunities, new options can also be offered for student-technology partnerships in learning. (Lim, Churchill, 2016) [13]. Students can watch videos about the subject, or read a passage before the lesson, followed by a discussion led by their teachers. It changes class time from one-way information dissemination to two-way knowledge discovery.

The pedagogical design should be shifted from teacher centric to student centric. Instead of one-way information delivery from teacher to students, teachers today need to perform multiple roles (i.e. facilitator) in motivating, facilitating and enabling learning in varied contexts to cater for students' diverse learning needs. (the Education Bureau, 2017) [1]. With the use of electronic devices, students can record and share ideas and comments on a given topic with a real audience online. Students learn more actively and effectively when they take ownership of the ideas and information shared (the Education Bureau, 2017) [1]. A tablet PC can facilitate the discussion process. Students can write, draw or video record their ideas and opinions and submit to the teacher screen through the cloud network. Teacher can then immediately capture the center ideas of the discussion in the class through reading the tag cloud display, which highlights the most frequently submitted keywords. In this way, students can shape their own opinions and ideas, to make their own decisions, and contribute more in the knowledge discovery process. Providing students with the task of developing their own learning, turns them to their own resources, which develops their emerging individuality and helps them to rehearse more as knowledge explorer. As they become more self-directing, they not only learn effectively but also built a better sense of ownership of the knowledge that they discover.

Second, we should also foster an environment for students to challenge themselves to unleash their best possible performance. With the promotion of assessment as learning, students are given opportunities to learn about the use of rubrics and success criteria; to conduct self and peer assessment, which help develop their ability to monitor and evaluate their own learning (the Education Bureau, 2017) [1]. Teachers could first challenge students through online quizzes and then encourage them to challenge themselves.

Third, providing timely feedback to the students is very important to keep their interest and momentum, after taking challenges. Besides automatic marking of structural questions such as multiple choices, fill-in-the-blank and matching question types, a platform to facilitate peer assessment and learning is essential to learn from one another and learn how to assess and give comments to peers' works. The learning motivation could be further enhanced by mutual learning and reflection.

\section{CASE Study In A Primary SchOOl In Hong Kong}

In an e-learning deployment project with Fung Kai Primary School in Hong Kong, diversified IT tools are utilized to facilitate SDL that helps develop students' learning habits and techniques in class or after class. Teaching and learning effectiveness are also greatly enhanced as students are actively participating in these learning activities to show their learning interests and what they have learnt.

\section{A. iClass Learning Management System}

Online platform called 'iClass' developed by the e-Learning Development Laboratory of the University of Hong Kong (URL: http://elearning.eee.hku.hk). It is a cloud-based platform that allows students to use the iPad or smart phone to communicate with the teachers' platform, as shown in Fig. 1.

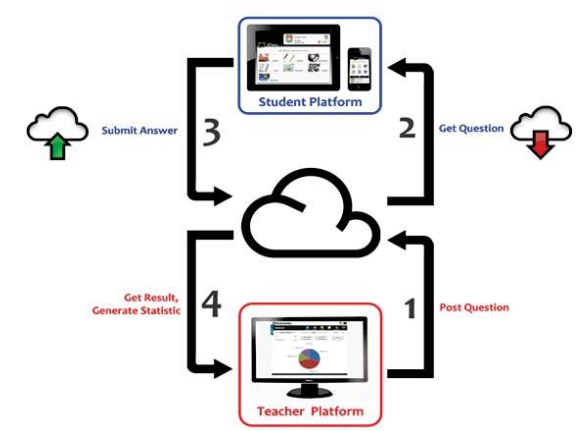

Fig. 1. System block diagram of the iClass cloud-based mobile interactive system.

Flipped lesson which is an animation from Powtoon, is applied to reduce the amount of time spent in class on lecturing. It gives students a greater sense of their own responsibility for their learning as they have to be well prepared before they attend the lesson. As most of the students are able to master the knowledge through flipped lesson, teacher can use the excess time to implement more dynamic learning activities, for instance matching, brainstorming, role-play, group discussion, case studies, simulation or other learning activities. Moreover, teachers are better enabled to provide some tailor-made resources and other related materials to arouse students' learning interests, facilitate their learning, and consolidate what the learnt. These helps establish an authentic and interactive learning environment, as well as foster and develop students' attitudes towards self-directed learning and communication skills among peers.

\section{B. Pedagogical Design}

A lesson under investigation was designed to be divided into three teaching and learning stages:

1) Teacher asked students to browse some websites and watch a tailor-made animated video about the key vocabulary and grammar items.

2) Students got or peruse some related information from the websites and flipped video. Followed by watching the video, they were required to finish a mini task 'Drawing' after they enjoyed the video. (Fig. 2)

3) Students were asked to take photos and write sentences of their daily experiences and what they have learnt. 


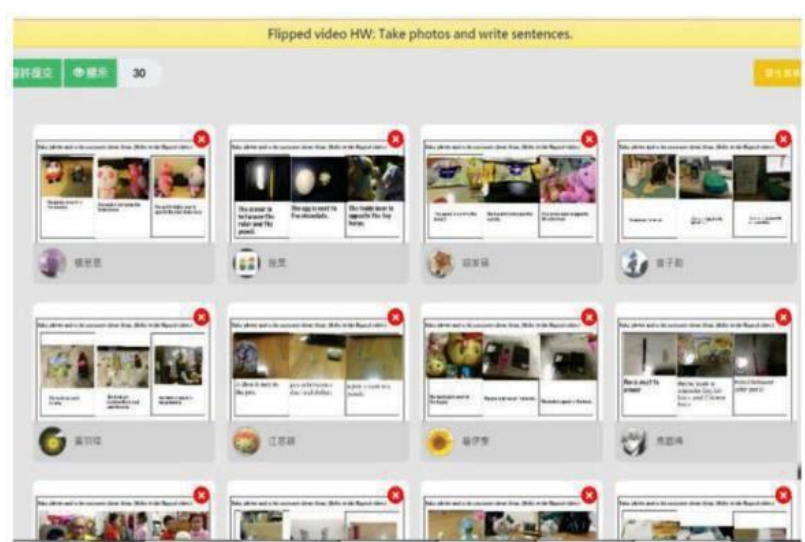

Fig. 2. Students' submission of their exploration on the flipped videos with photos and description using iClass drawing function.

The way to drive flipped classroom to the focus, students should be encouraged to develop their self-directed learning attitudes; elicit their thinking and learning interests and therefore increasing their engagement level. With a well-presented platform, teachers can monitor and assess students' learning performances base on their work in these sections. Students can watch the flipped lesson without limitations and according to their needs; they may pause or repeat when they reach challenges. Lecture time can be flexibly used to implement other remedial or enrichment activities, while students can develop their own learning habits and styles.

Teacher uses iClass 'Keywords' to recall and revise students' learnt knowledge in class. This helps create a contextual learning environment.

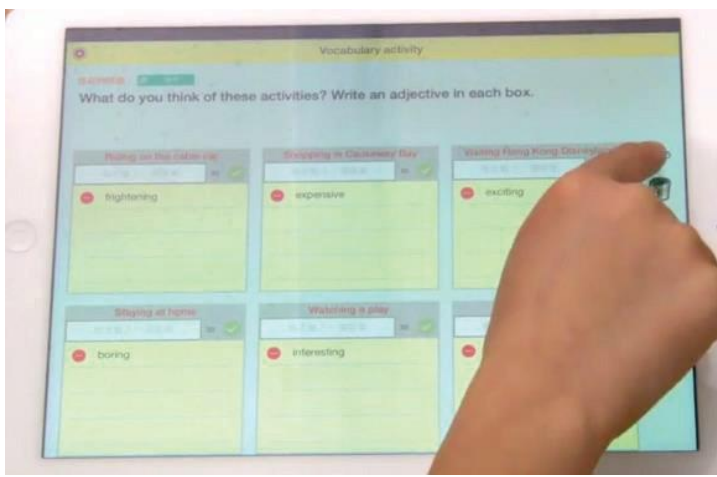

Fig. 3. Evaluation and vocabulary-learning activity using iClass keywords function.

A quick sharing of students' homework shows what the students' learnt (Fig. 4). Some students can type words others than the vocabulary in video to show their self-directed learning.

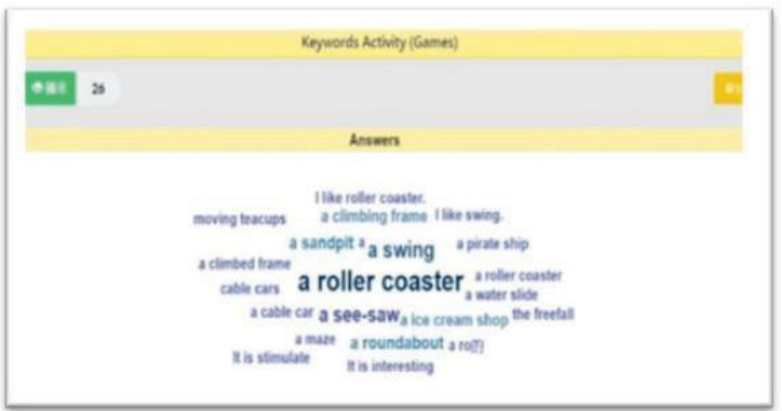

Fig. 4. Tag cloud displayed brianstorming ideas or contributions from students in the class.
Students use fingers to drag and drop the stickers or choose the answers easily. (Fig. 5) Students enjoy learning while teacher can monitor learning progresses and modify the teaching content. Follow-up tasks or enhancement activities can be held with the purpose of facilitating instant teaching and learning.

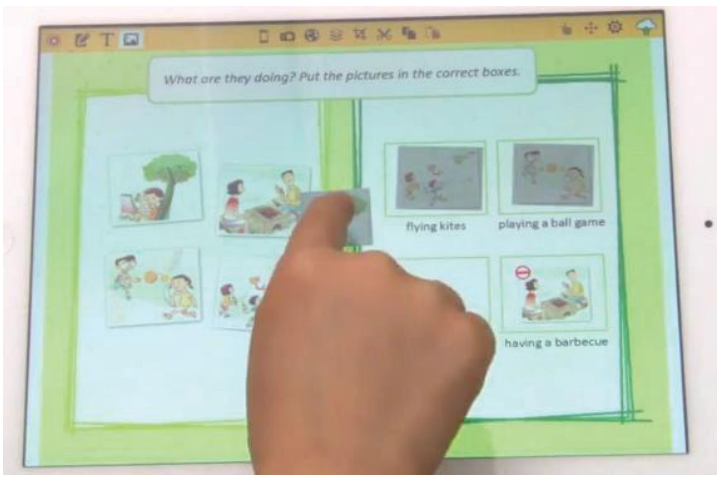

Fig. 5. Picture-text matching using iClass drawing function.

Pair-work and audio-recording activities (Fig. 6) provide an authentic situation for students to apply what they learnt, as well as develop their communication skills among peers.

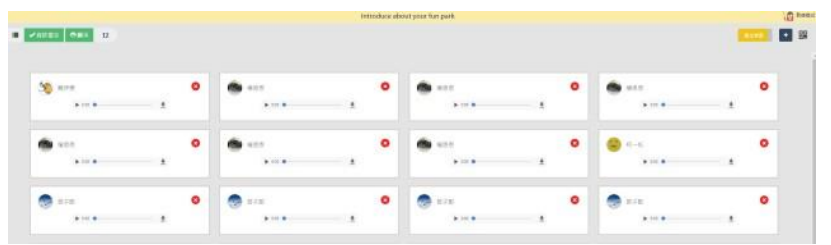

Fig. 6. Students' experience sharing using iClass audio-recording activities.

After reading English book contents, quiz challenge was followed. It involves reaching for a new level of performance in a familiar field or launching an adventure into a new field of interest. Such a quiz challenge, often associates with a score ranking table, could create an environment of friendly competition and effectively motivate students to self-learn.

Interactive matching, multiple choices and drawing activities are used to revise the key items quickly and actively as all students can take part in this activity when compare with non-BYOD (Bring Your Own Devices) lessons.

\section{FINDINGS}

\section{A. Method}

The data from this study were obtained from semi-structured questionnaire of $96 \%$ of the participants who participated in the conducted lesson. The questionnaire was conducted in English (as a second language), additionally aided with verbal instruction in Cantonese (native language) by the teacher.

\section{B. Unit Lesson}

The unit lesson was conducted in the topic of "At the Fun Park" across two 35-minute regular school-scheduled sessions.

Before the first lesson, students were required to watch a 5-minute video and finish several pre-class tasks containing a Drawing (for photo-sharing and texting) (Fig. 2) and a 
peer-review activity questions regarding the video. During the lesson, teacher led two games using Keywords (Figure 4), multiple-choice question to learn the themed vocabularies and a simple writing tasks "favorite game in Fun Park".

Following the first lesson, students were asked to read the e-book of preposition before the second class, followed by 3 jumbled drawing activities and an in-class test regarding "preposition". After a series of learning activities, students had to design their fun park and write sentences to describe their park. With the task requirement, students were encouraged to actively search for relevant information and media online. The pedagogical design of the lessons is described at Section III.

\section{The Participants}

The instructor and the 30 primary students were from Bring-your-own-devices (BYOD) class from Fung Kai No.1 Primary School, which has been one of the pioneer of e-Learning practice among the Primary schools in Hong Kong since 2003. Since December 2016, the students of BYOD class have started using their iPads for their learning in different subjects (including Native language, English-as-Second-Language (ESL) Mathematics and STEM education etc. in school based learning. With common practice to classroom management, all participants held their personal mobile devices. Students were managed with teachers' clear instructions on when and how to turn the device on for participating the e-Learning activities and interacting with teachers and peers.

According to the survey result, $67 \%$ of the participated students spend 15 to 30 minutes a day searching for information using a mobile platform. For English learning, they utilize it for checking spelling (87\%), finding writing passages $(87 \%)$, checking pronunciation $(77 \%)$, listening to audios $(53 \%)$ and finding videos $(50 \%)$, while $90 \%$ of them complete the assigned tasks and activities on iClass.

Among all students, they agreed and be neutral with the statement of "like finding information by themselves" and "feel more confident in learning by themselves with a mobile device than without it." In terms of the nature of the learning tasks, no one among them dislikes challenging tasks while $70 \%$ of them like challenges.

All the participants completed in the evaluation questionnaire voluntarily. The students were also informed that their participation, rejection, or incompletion of the questionnaire would not affect their grades in this lesson.

\section{Data Collection}

The data for this study were obtained from a designed online questionnaire on iClass for the instructor and 30 primary school students $(n=30)$ who participated in the lesson of the case study.

To cater for primary school students, the rate-scale questionnaire was designed for quantitative method, in the scale from 1(represents "Disagree") to 3 (represents "Agree") (Table I). For questionnaire designed for teacher, it was designed for qualitative method (Table I).

\section{E. Data Analysis}

\section{1) Participation rate}

Based on the total 30 participants, submission rate of all the pre-lesson flipped activity is $100 \%$ while in-class activities submission rate is $92 \%$. Overall, students were actively participated in all activities under teacher's instructions, even though some could not complete the task in class.

2) Learning effectiveness and engagement level of flipped learning with mobile platform

$74 \%$ of the participants agreed that watching the video before lesson can help them learn quicker in lesson, meanwhile $85 \%$ of them found doing an activity (e.g. Drawing) after watching the video is interesting.

TABLE I: QUESTIONS ON THE QUESTIONNAIRE FOR STUDENTS

1. I like finding information by myself. (Rate 1 :Disagree to 3:Agree) 2. Watching the video before lesson helped me to learn quicker in lesson.(Rate 1 :Disagree to 3:Agree)

3. I find doing an activity (e.g. Drawing) after watching the video is interesting. (Rate1 :Disagree to 3:Agree)

4. "Video" activity on iClass can help my English listening and speaking skills. (Rate 1 :Disagree to 3:Agree)

5. "Audio" activity on iClass can help my English listening and speaking skills. (Rate 1 :Disagree to 3:Agree)

6. "E-book" activity on iClass can help my English reading skills. (Rate 1 :Disagree to 3:Agree)

7. "Open-end" writing activity on iClass can help my English writing skills. (Rate 1 :Disagree to 3:Agree)

8. What do you like about Keywords activity? (multiple answer)

9. I like the challenging activities (e.g. Drawing, MC, and quiz).

10. In-class quiz/test help me to keep a better memory.

(Rate 1 :Disagree to 3:Agree)

11. What can you learn from Peer Review? (multiple answer)

12. How frequent do you use mobile devices to learn/ search for information for a day?

13. I feel more confident in learning by myself with a mobile device than without it.(Rate 1 :Disagree to 3:Agree)

14. For what reason(s) do you use iPad/ Tablet to learn English? (You can choose more than one)

TABLE II: EXAMPLE OF INTERVIEW QUESTIONS WITH THE TEACHER

1. How do you describe the reaction and engagement level of students learning English with and without mobile device and LMS activities?

2. Did you apply other e-Learning Learning Management System for teaching?

3. How do you describe the usability of iClass?

3) Learning effectiveness and engagement level of learning English with mobile platform

$56 \%$ of students agreed that "Video" and "Audio" activities on iClass can help their English listening and speaking skills while "E-book" activity can help their English reading skills; $70 \%$ of them agreed "Open-end" writing activity can help their English writing skills.

4) Assessment as learning

Around half of the students believe that in-class quiz or test help them to keep a better memory to the learnt knowledge.

5) Peer and self-assessment

The result shows a very positive impact of the peer review activities on iClass: it gives students the way to know others ideas and thoughts $(87 \%)$, learn how to mark against the criteria (80\%), appreciate and write a comment to others (77\%).

With similar nature of peer learning, keywords activities has shared peer-learning function. Research shows that the majority of the student participants like the keywords activities helps them to know others' ideas (83\%), group ideas $(80 \%)$, learn vocabularies $(77 \%)$ and share writing 
ideas with others $(77 \%)$.

\section{F. Impact on Teaching Quality and Learning Effectiveness}

1) Students' learning

Both teacher and students can share and appreciate peers' work on the platform by giving scores or commenting to their classmates' work through the

'Peer-review' activity. This provides opportunity for students to appreciate others' work and learn from each other, creating a co-learning atmosphere.

2) Teacher's teaching and facilitation

According to interview result from the instructor, the students were highly engaged when it came to learn and interact with the LMS, which comprehensively manage all resources and created activities, plus making flipped learning a greater impact for pre, during and post lesson.

Teachers knows how to apply pedagogical designs with the LMS platform effectively in teaching, producing attractive and useful flipped materials for students to develop their own learning habits and styles, which makes a good drive towards self-directed learning.

The instructor has experienced utilizing different e-Learning platforms to apply to teaching, while she finds that iClass shares a much user-friendly interface and operation to both teachers and students as a whole.

Both parents and students can revisit the course materials at home as revision or evaluation after class. Teachers and students can greatly beneficial through e-learning as it really enhances the effectiveness of teaching and learning as well as facilitate and develop SDL of students and teachers.

\section{EVALUATION AND FURTHER WORKS}

The key success factor of self-directed learning is developing an effective self-autonomy for students'. Many principles of motivation are built into the design of SDL, such as the pursuit of one's own high-interest goals. By setting important goals for themselves, arranging for feedback and self-assessment on their work and performance could help inspire students. They can negotiate and agree the assessment method with their teachers and take the responsibility for collecting evidence of achieving their goals. To support students' learning, the facilitation of using the e-portfolio function on iClass (Fig. 7) so that students can generate records of their works submitted through the self-learning activities. This e-portfolio will be a practical tool for both students and teachers to evaluate their works and achievements, meanwhile facilitating their presentation to the universities for further studies.

Last but not least, large amount of data will be collected from students through their self-directed learning process in the future. Finding solutions to analyze these data in an effective and intelligent way will be the new challenges. We need to find out online self-learning behavioral data such as the browsing duration, breadth and depth of the SDL, common mistakes in the on-line quiz, and score distribution of the class. A good Learning Management System could provide such analytic data for teachers and parent to monitor the progress and efficiency of the self-directed learning of the students.

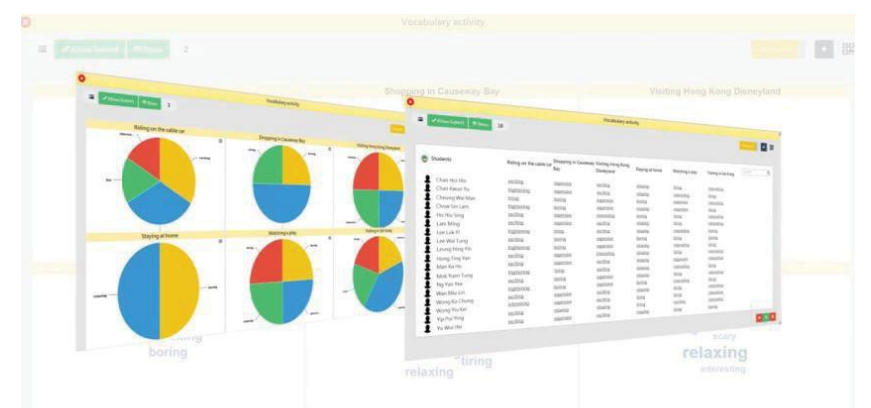

Fig. 7. Generated record of students' contribution of participated works can be shown on graphic and list view with e-portfolio.

A scaled research shall be better conducted within a wide range of educational contexts and with learners of various backgrounds. This study was supported by a BYOD class in a primary school with adequate number of participants. Further studies will involve higher number of participants from different schools with different degree of hands-on technology education practices.

\section{CONCLUSION}

The case study of learning English with mobile learning platform gives us an encouraging evidence that the iClass Learning Management System provides teachers and learners with a quality pedagogy design tools for achieving self-directed learning.

The e-portfolio and statistic reports can keep track with students learning progress while teachers can notice the learning diversity within the class. Undeniably, the use of technology can cater for learning differences, engaging students of diverse abilities and interests. (The Education Bureau,2017) [12]. This gives us another challenge to continuously develop for a more engaging and customised learning plan for individuals.

The development of SDL helps promote students' lifelong learning attitudes. Students can learn spontaneously and actively through SDL and thus their academic performances and results are expected to be highly promoted.

\section{REFERENCES}

[1] The Education Bureau HKSARG, Secondary Education Curriculum Guide: Effective Learning and Teaching. the Education Bureau, HKSARG, the Curriculum Development Council, Hong Kong: the Education Bureau, HKSARG, 2017.

[2] K.-H. Agnes and S. Lesley, "An overview of mobile assisted language learning: From content delivery to supported collaboration and interaction," ReCALL, 2008.

[3] J. Attewell, "Mobile technologies for learning," London: Learning and Skills Development Agency, 2005.

[4] D. Churchill et al., "Using handhelds to support students' outdoor educational activities," International Journal of Continuing Engineering Education and Life-Long Learning, vol. 20, no. 1, pp. 54-72, 2010.

[5] N. Kaleebu et al., "SMS story impact assessment report," VSO, Papua New Guinea, 2013.

[6] C. K. Looi et al., "Leveraging mobile technology for sustainable seamless learning: A research agenda," British Journal of Educational Technology, vol. 41, no. 2, pp. 154-169, 2010.

[7] M. Ratto et al., "The active class project: Experiments in encouraging classroom participation," 2003. 
[8] R. Shen et al., "Mobile learning in a large blended computer science classroom: System function, pedagogies, and their impact on learning," IEEE Transaction on Education, vol. 52, no. 4, pp. 538-546, 2009.

[9] Y. Song and R. Fox, "Using PDA for undergraduate student incidental vocabulary testing," ReCALL, vol. 20, no. 3, pp. 290-314, 2008.

[10] L. H. Wong et al., "Students' personal and social meaning making in a Chinese idiom mobile learning environment," Educational Technology \& Society, 2010.

[11] L. H. Wong and C. K. Looi, "What seams do we remove in mobile-assisted seamless learning? A critical review of the literature," Computers \& Education, vol. 57, no. 4, pp. 2364-2381, 2011.

[12] G. Zurita and M. Nussbaum, "Computer supported collaborative learning using wirelessly interconnected handheld computers," Computers \& Education, vol. 42, pp. 289-314, 2004.

[13] L. Churchill, "Interactive learning environment," Mobile Learning, vol. 24, no. 2, pp. 273-276, 2016.

[14] T. Long et al., Journal of Teaching and Learning with Technology, 2016.

[15] G. Gannod et al., "Using the Inverted classroom to teach software engineering using the inverted classroom to teach software engineering," presented at the 30th International Conference on Software Engineering $2008,2008$.

[16] J. Gerstein, The Flipped Classroom Model: A Full Picture.

[17] N. Warter-Perez and J. Dong, "Flipping the classroom: How to embed inquiry and design project into a digital engineering lecture," presented at American Society for Engineering Education-Pacific South West Section Conference, 2012April.

[18] G. Stockwell, "Vocabulary on the move: Investigating an intelligent mobile phone-based vocabulary tutor," Computer Assisted Language Learning, vol. 20, no. 4, pp. 365-383, 2007.

[19] H. Lee and J. H. Lee, "Implementing glossing in mobile-assisted language learning environments: Directions and outlook," Language Learning \& Technology, vol. 17, no. 3, pp. 6-22, 2013.

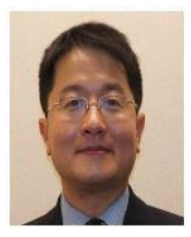

Wilton Fok is the assistant dean of engineering and the director of the e-Learning Development Laboratory of the Department of Electrical and Electronic Engineering of the University of Hong Kong. Dr. Fok and his research team had developed an interactive mobile platform called iClass for the enhancement of real-time interactive teaching and learning since 2011 . The project was used not only in the University of Hong Kong but also in many schools and universities in Hong Kong, mainland China, United States, United Kingdom and Singapore. The project awarded the Hong Kong Information Communication Technology Award in 2011 and 2013. Dr. Fok also received the Best Teacher Award from the Faculty of Engineering in 2010, the Outstanding Teaching Award (Team Award) in 2014 and the Faulty Outstanding Teaching Award in 2015. Dr. Fok is a co-chair of the Global Conference on Teaching and Learning with Technology (CTLT 2016) and an invited keynote speaker of the 6th Annual International Conference on Education \& e-Learning (EeL 2016).

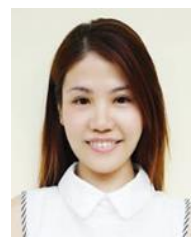

K. W. Lam is an experienced English teacher of Fung Kai No.1 Primary School. She is one of the teachers that responsible for English IT teaching in school and support promoting e-learning practice for several academic years, including e-Learning pedagogies learning, knowledge sharing, platform and lesson implementation in school since 2013. She also participated in several competitions actively. She received the Gold award and the Second Runner-up of the International Outstanding e-Learning Awards in 2015/16 and 2016/17 which were organized by the University of Hong Kong and co-organized by Oxford University Press (China) respectively. Her teaching mission is to facilitate the effectiveness of teaching and learning in school, such as encouraging students learning motivation and the development of individual learning styles. This will aid the learning and teaching English as it is a really challenging subject for students.

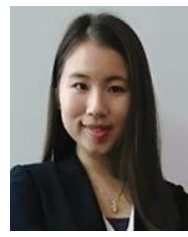

Prajna C. W. Ho is a research project assistant of iClass team in the e-Learning Development Laboratory of the Department of Electrical and Electronic Engineering of the University of Hong Kong. With her experience in the coordination for the Professional Development \& Training courses of the Education Bureau, HKSARG, for school teachers in Hong Kong; she has devoted herself to deliver the best possible instructional design, teaching materials enhancement and education management. She received The Department of Management Sciences Student Development Scholarships in 2016 and Student Exchange Fund in 2015 from the City University of Hong Kong. She is also an awardee and member of Sir Edward Youde Scholars Association since 2010 . 